\title{
The CURRent State of THE USE OF SElECTEd INDUSTRY 4.0 TECHNOLOGIES IN MANUFACTURING COMPANIES
}

\author{
Martin Polivka \& Lilia Dvorakova
}
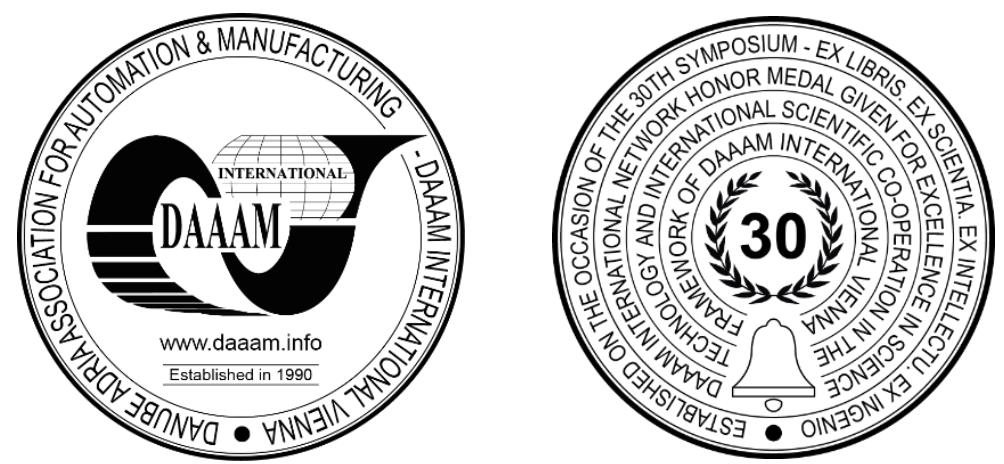

This Publication has to be referred as: Polivka, M[artin] \& Dvorakova, L[ilia] (2021). The Current State of the Use of Selected Industry 4.0 Technologies in Manufacturing Companies, Proceedings of the 32nd DAAAM International Symposium, pp.0652-0659, B. Katalinic (Ed.), Published by DAAAM International, ISBN 978-3-902734-33-4, ISSN 1726-9679, Vienna, Austria

DOI: $10.2507 / 32$ nd.daaam.proceedings.092

\begin{abstract}
The technologies of the Fourth Industrial Revolution (Industry 4.0) include both technologies related to the physical aspect of production process, and those related primarily to data and information infrastructure, whose deployment in enterprises affects their IT landscape including the Enterprise Resource Planning (ERP) system. The research aims to identify the Industry 4.0 technologies that have a direct impact on ERP systems and to determine the current level of use of these technologies in medium-sized and large industrial enterprises in the Czech Republic. Based on the deductive analysis, Industry 4.0 technologies having a direct impact on ERP systems are identified, and data obtained from the questionnaire survey are statistically processed. Big data, system integration, cloud, and automatic identification and data capture have been evaluated as the Industry 4.0 technologies that have a direct impact on ERP systems. The research results document that the technology of in-house system integration is the most frequently used one. The ongoing research is directed at analysing the reasons for this finding in order to evaluate why the other technologies are not used more intensively and how enterprises make decisions on the choice of technical solution when deploying technology.
\end{abstract}

Keywords: ERP systems; Industry 4.0; Industry 4.0 technologies; Information systems

\section{Introduction}

The last decade has seen the emergence of a number of technologies in the field of informatics and cybernetics that have the potential to significantly influence the shape of the future economy as well as the entire society. The development and the increasingly widespread practical use of these technologies are collectively referred to in the literature as the socalled the "Fourth Industrial Revolution", which is expected to result in the emergence of "Industry 4.0" or, in the broader sense, the entire "Society 4.0" [1], and especially in Japan, they even use the term "Society 5.0" in this context (see, for example, [2], [3] or [4]). The defining feature of this new environment is, above all, to be the close connection between physical and virtual reality and the maximum possible degree of cooperation between humans and machines (for more details see, e.g., [5] or [6]). The spectrum of technologies considered to be part of the Fourth Industrial Revolution is very broad and includes technologies mainly from the fields of digitization, automation, robotics, and artificial intelligence. Some of these technologies relate especially to the physical aspect of the production process, and their implementation is thus primarily reflected in changes in the layout and operation of production lines. 
However, there are also technologies of the Fourth Industrial Revolution that primarily involve data and information infrastructure. Their deployment in the enterprise will thus primarily affect company information systems and technologies and they are referred to as the "IT landscape" (see, e.g., [7]). Changes in the enterprise's IT landscape will then logically affect its central element, which is the company ERP system.

\section{Research objectives and methods}

This paper presents research which, firstly, aimed to identify the technologies of Industry 4.0 that have a direct impact on ERP systems and, secondly, to determine the current state of the use of these technologies in industrial companies in the Czech Republic. The research method used for the first objective was the desk research of existing literature on Industry 4.0 technologies combined with the deductive analysis, the principles of which are presented in Chapter 3 . To achieve the second objective, data were collected by means of a questionnaire survey conducted at the beginning of 2021 in medium-sized and large industrial enterprises in the Czech Republic. A total of 1,758 enterprises were successfully approached to fill in the questionnaire and 68 of them completed the questionnaire. Therefore, the return rate of the questionnaire was approximately $4 \%$. The data were then statistically processed, and, considering the nature of the data, the non-parametric Kruskal-Wallis test combined with the Nemenyi method was chosen for more detailed analysis. The detailed description of the questionnaire survey, together with the analysis and discussion of the results, is presented in Chapter 4.

\section{Relevant technologies of the industrial revolution}

Since the use of the term "Industry 4.0" has recently undergone some inflation [8], and is thus used in the multitude of meanings, it is possible to encounter a variety of technologies that are described as part of it in various academic papers, but the list of these technologies varies significantly depending on the opinion of a particular author. Hence, some papers emphasize cyber-physical systems, the Internet of Things and cloud computing (e.g. [9]) or even edge computing [10], while other authors stress the importance of augmented reality [11] and digital twin [12], collaborative robots [13] or blockchain [14].

The inconsistency in the definition of technologies of the Fourth Revolution is logical on principle, since the estimation of the fact which technologies will see mass diffusion in the future and significantly influence the shape of the economy is ultimately largely arbitrary and depends on the opinion of a particular author or institution. However, for the purposes of the research presented here, it was necessary to first define a core set of technologies from which the technologies with a direct impact on a firm's ERP system could be selected on the basis of the analysis.

Therefore, the so-called "9 Pillars of Industry 4.0" were used as a core set of technologies for further selection in our research. This term, introduced by Rüssman et al. [15] and adopted by many other authors (see, e.g., [6] or [16]), refers to nine technologies (or technological areas) that are the basic building blocks of "Industry 4.0". The core technologies are as follows:

1. Big data

2. Autonomous (collaborative) robots

3. Simulations

4. System integration

5. The Internet of Things

6. Cyber-physical systems

7. Cloud technologies

8. Additive manufacturing

9. Augmented reality

In addition to these nine pillars, some authors add the tenth pillar, collectively referred to as "Other Technologies", which contains advanced technologies with a narrower focus, always applicable only for the purposes of selected industries (cf. [17]). However, based on the analysis presented in the study of Polívka and Dvoŕáková [18], the authors of this article believe that it is possible to identify one more modern technology the development of which has a similar impact on the course of the "Fourth Industrial Revolution" as the aforesaid 9 pillars and which is also universally applicable across industries. This technology is Automatic Identification and Data Capture (AIDC), which has been added to the nine pillars listed above for the reasons given above.

The first objective of the research was to identify within these ten core technologies those that are directly related to the issue of ERP systems. The basic starting point of the analysis was the fact that the ERP system is the central element of the enterprise's IT landscape, where the summary data on all business processes are concentrated. These data are subsequently reported and further evaluated within the ERP system and serve as a basis for further management of the enterprise. However, not all of these data are directly collected within the ERP system. ERP systems usually manage both administrative processes, such as invoicing or accounting, and cross-section processes using data from the entire organisation, such as central purchasing and production planning. However, the actual operational management of physical processes, such as production or logistics, is rather the domain of specialized, narrowly focused systems such as Manufacturing Execution System (MES), Warehouse Management System (WMS), etc. 
Compared to these narrowly focused solutions, ERP systems do not have comparable functionality in this area, and due to their technical nature, they are not suitable or even not at all applicable for direct management of some physical processes. Typically, these are situations where the production management system has to communicate online with production machines and equipment, and the communication protocol requires a feedback speed of milliseconds. However, such response time is technically not necessarily achievable in the case of ERP systems containing large, highly interconnected databases with a high degree of business logic.

Therefore, in the first part of our research, technologies that are primarily related to the management of administrative processes and/or the evaluation of centralized data were selected from the core set of ten Industry 4.0 technologies, as these are the main domain of ERP systems. Big data, system integration, cloud, and automatic identification and data capture have been evaluated as such technologies.

As far as the technology of big data is concerned, in order to use it, an enterprise must be able to collect large volumes of primary data, and it must be able to store and evaluate them. Even for the actual collection of data on some processes, the interaction of ERP system is necessary - while data describing physical processes are collected primarily through sensors and detectors, the progress of administrative processes is usually monitored in the form of records in the ERP system, through which these processes are controlled and coordinated. In order to ensure appropriate storage and analysis of the collected big data, the ERP system must then contain suitably designed, sufficiently robust data structures, and must either have powerful tools for their evaluation itself, or at least be able to cooperate with specialized analytical tools. It is therefore clear that the technology of big data is directly related to ERP systems.

System integration consists in the interconnection of information systems and the exchange of data between them either within the company (sometimes referred to as vertical integration) or across the supply and customer chain (the socalled horizontal integration). Although individual integration solutions differ significantly in practice, both in terms of technical solution and functionality, ERP systems usually act as one of the basic elements. In the case of in-house integration, the usual scenario is the connection of partial, specifically focused subsystems (e.g., in the form of MES, WMS or PLM systems) to the central element of the company IT landscape represented by the ERP system, while horizontal integration across the supply and customer chain logically concerns mainly mutual business relations between companies, which are represented in data terms by the circulation of orders and invoices, while these entities are normally recorded and processed within ERP systems.

As far as the cloud technology is concerned, it enables the transfer of data repositories (and possibly other elements of the IT landscape, e.g., in the form of application servers) to a shared environment operated by the provider and accessible via the Internet. It is therefore closely linked to the issue of enterprise information systems, which, in the case of transfer to the cloud, are no longer operated in the internal environment of the company, but their availability is provided to the company in the form of a service. ERP systems are the part of the IT landscape that is a suitable candidate for the transfer to the cloud - on the one hand, the ERP system as a central hub of the information system contains a large amount of data, for the effective processing of which local devices may not be sufficient, and on the other hand, unlike operational systems such as MES or WMS, it is not a business critical application whose temporary failure would completely stop the operation of the company. The short-term unavailability of cloud services caused by, for example, physical interruption of data lines can thus be viewed as an acceptable risk, which affects only administrative processes, but does not entail costs such as the complete stoppage of production, inventory devaluation, etc.

Although the technology of automatic identification and data capture is seemingly associated primarily with physical devices in the form of sensors or detectors, these devices are only tools for the automated data acquisition (whether they are accounting or business data in the case of machine document mining or data on the physical movements of goods, materials and products obtained by reading barcodes or RFID transponders). Then, these data are again processed, stored, and analyzed in central information systems, typically in ERP. Therefore, this technology is also closely related to the ERP issue.

As for the other technologies of the Fourth Industrial Revolution, these are primarily related either to physical processes (in the case of autonomous robots and additive manufacturing) or to their software control (in the case of simulations and cyber-physical systems) and the acquisition of data for this control (in the case of the Internet of Things). Therefore, they are not primarily related to ERP systems and were not included in the following part of the research.

\section{The questionnaire survey results and discussion}

To obtain information on the current use of the four "Industry 4.0" technologies identified as relevant in relation to ERP systems in the Czech Republic, a questionnaire survey was carried out as part of a broader study examining the extent to which "Industry 4.0" influences the requirements that companies place on ERP systems and the process of selecting such systems.

Three criteria were applied when selecting the basic population. From the geographical point of view, companies based in the Czech Republic were selected, which corresponds to the defined research objectives. The size of enterprises was chosen as the second criterion, where only those falling into the category of medium-sized and large ones according to the EU categorization, i.e., enterprises with more than 50 employees and an annual turnover of more than EUR 10 million, or a balance sheet total of more than EUR 10 million, were selected for the survey. The size criterion was used to define the basic population because the implementation of Industry 4.0 technologies is, primarily due to the investment costs associated with that, still mainly a matter of large and medium-sized enterprises [19]. 
Similarly, ERP systems are mostly used in medium-sized and large enterprises, while micro and small ones often still manage with simple accounting and business software. Conducting such a focused survey in micro and small enterprises would thus be unlikely to yield relevant data for these reasons. The third criterion was the sector in which the enterprises operate, where enterprises in the manufacturing industry, i.e., those falling under section "C" of the Czech Statistical Office's classification, were selected for the basic population. The reason for defining the specific sector is that although Industry 4.0 is no longer considered exclusively a matter of manufacturing companies, as evidenced by the existence of terms such as "Agriculture 4.0", "Logistics 4.0" or the general term "Society 4.0", yet it is manufacturing and especially the so-called "smart factories" that are most closely linked to this concept [20]. It is therefore logical to examine the current state of the use of Industry 4.0 technologies in this particular environment.

A total of 1,758 companies were approached to participate in the survey. Companies were asked to have employees who are either key users of the ERP system or IT managers responsible for the operation of the ERP system in the company complete the survey. The questionnaire was completed by the representatives of 68 enterprises, so the return rate was about $4 \%$. In the questionnaire, the four selected technologies were assessed individually, with the system integration technology further divided into the horizontal and vertical ones. For each technology, excluding the cloud, the respondents were asked two questions to establish the following facts:

1. Whether the company uses the technology.

2. If the company uses the technology, what specific technical solution is implemented.

As for the cloud technology, the respondents were only asked the first question mentioned above. This is because the technical nature of the cloud is homogeneous on principle. Although there are, of course, different options of using cloud services as well as different options of their hosting, from the technical point of view it is ultimately always about providing server resources in the form of a service. The second question would thus be irrelevant in the case of cloud technologies.

The questions were closed-ended, and in the case of the first question, the answers were defined by a five-degree scale, with each degree also described verbally for better understanding by the respondents. The specific wording of each question and possible answers are available from the authors of the paper. The possible answers to the second question were then defined by a list of potentially applicable technical solutions. The answers to the first set of questions investigating to what extent firms use individual technologies are shown in Table 1:

\begin{tabular}{|c|c|c|c|c|c|c|}
\hline \multirow{2}{*}{ Technology } & \multicolumn{5}{|c|}{$\begin{array}{c}\text { Response frequency on the scale of } 1-5(1=\text { technology is not used at all, } \\
5=\text { technology is used with the maximum intensity })\end{array}$} & \multirow{2}{*}{ Average } \\
\hline & 1 & 2 & 3 & 4 & 5 & \\
\hline Big data & 9 & 12 & 29 & 11 & 7 & 2.93 \\
\hline $\begin{array}{l}\text { In-house system } \\
\text { integration }\end{array}$ & 4 & 4 & 12 & 19 & 29 & 3.96 \\
\hline $\begin{array}{l}\text { Inter-company } \\
\text { system integration }\end{array}$ & 24 & 17 & 8 & 16 & 3 & 2.37 \\
\hline Cloud solutions & 14 & 19 & 29 & 4 & 2 & 2.43 \\
\hline AIDC & 26 & 11 & 15 & 14 & 2 & 2.34 \\
\hline
\end{tabular}

Table 1. The rate of the use of the selected Industry 4.0 technologies in industrial enterprises in the Czech Republic.

As can be seen from Table 1, the most used Industry 4.0 technology related to ERP systems in the conditions of Czech manufacturing companies is clearly in-house system integration, i.e., the interconnection of several information systems. Big data have been evaluated as the second most used technology; however, the rate of its use is significantly lower compared to the in-house system integration. According to the respondents, the remaining technologies examined are used to a comparable, and relatively small, extent.

Whether the observed differences between the use of different technologies are indeed a statistically significant phenomenon or merely a random variation was further examined by means of the Kruskal-Wallis test, which tests the null hypothesis of distribution functions concordance of more than two random variables. The non-parametric KruskalWallis test was chosen instead of the ANOVA test, which assumes the normality of data, both because of the nature of the input data (discrete values in a limited range) and because of the limited sample size. The Kruskal-Wallis test criterion was calculated according to equation (1):

$$
H=\frac{12}{N(N+1)} \sum_{i=1}^{C} \frac{R_{i}^{2}}{n_{i}}-3(N+1)
$$

Where $C$ is the number of groups, $n_{i}$ is the number of observations in a group, $N$ is the total number of observations in all groups, and $R_{i}$ is the sum of the rank of the members of the $\mathrm{i}$-th group. 
The calculated value of the criterion was 66.78 . This value was compared with the critical value given by the $\chi^{2}$ distribution with $(C-1)$ degrees of freedom. At significance level $\alpha=0.01$, this critical value is equal to 13.27. The value of test criterion $H$ therefore exceeds the critical value and the concordance hypothesis of the distribution functions of the individual groups can thus be rejected. Therefore, the differences in the use of individual technologies can be declared statistically significant.

However, the Kruskal-Wallis test only shows that some of the examined random variables have a different distribution function than the others, without allowing a detailed analysis of these differences. Therefore, to compare in detail which technologies are statistically significantly more used than the others, the Nemenyi method was used, which allows the mutual comparison of the individual variables. The principle of this method is to compare the absolute value of the difference in the average ranking of each of the two groups examined with the value of the test criterion, which is calculated for the given sample range according to equation (2):

$$
K=q_{\alpha}(C, \infty) \sqrt{\frac{1}{12} C(C m+1)}
$$

Where $\mathrm{q}_{\alpha}(\mathrm{C}, \infty)$ is the critical value of $\mathrm{C}$ distribution of independent random variables with a normal distribution at significance level $\alpha$ and $m$ is the sample range in one group (i.e., for equal group sizes, $m$ equals any $n$ from equation 1). In our case, the critical value equals 54.87 at the significance level of 0.01 .

The results of the Nemenyi method for the first question are shown in Table 2, with statistically significant differences indicated by an asterisk (Note that values below the diagonal are not completed as they would mirror the values above it.):

\begin{tabular}{|c|c|c|c|c|c|}
\hline Technology & Big data & $\begin{array}{c}\text { In-house system } \\
\text { integration }\end{array}$ & $\begin{array}{c}\text { Inter-company } \\
\text { system integration }\end{array}$ & Cloud & AIDC \\
\hline Big data & 0 & $72^{*}$ & 40.38 & 36.70 & 42.10 \\
\hline $\begin{array}{c}\text { In-house system } \\
\text { integration }\end{array}$ & & 0 & $112.38^{*}$ & $108.70^{*}$ & $1.72 *$ \\
\hline $\begin{array}{c}\text { Inter-company } \\
\text { system integration }\end{array}$ & & & 0 & 3.68 & 5.40 \\
\hline Cloud & & & & 0 & 0 \\
\hline AIDC & & & & & 5 \\
\hline
\end{tabular}

Table 2. The results of the Nemenyi method in comparison with the use of the selected "Industry 4.0" technologies

Table 2 shows that only the rate of the use of in-house system integration is statistically significant compared to the other technologies. Although the use of the big data technology appears to be higher than the other three technologies based on the results at first glance, the hypothesis of their concordance cannot be rejected at the significance level of 0.01 , and it must therefore be assumed that this difference is caused only by a random deviation in the sample. In terms of the specific technical solutions used by the companies within the individual technologies, the frequency of each variant is shown in the following series of figures.

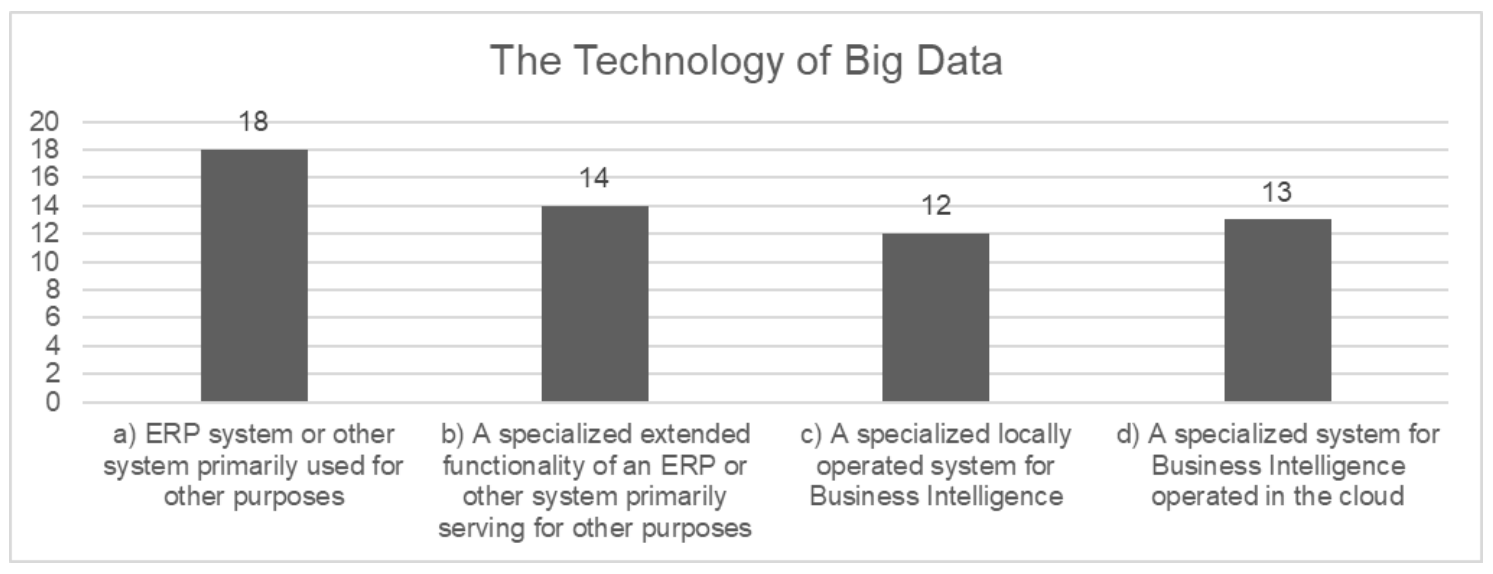

Fig. 1. The frequency of the specific technical solutions within the technology of big data 
Only those technical solutions that are used by at least one responding company are shown in the figures; the complete list of technical solutions that were offered to respondents as possible answers in the questionnaire can be requested from the authors of this paper. The sum of frequencies of individual technical solutions for each technology does not have to correspond to the number of the respondents. Not all the companies of respondents use all technologies, while other companies may use several different technical solutions within one technology.

As can be seen from Figure 1, which shows the frequency of the specific technical solutions used for big data, the companies that participated in the research are still using systems primarily designed for other purposes in the slight majority of cases. This option, represented by responses a) and b), occurred in a total of 32 companies. Eighteen of these companies do not even have any specialized module for dealing with large volumes of data within their information system and thus they have to manage with the standard functionalities offered by their system. On the other hand, twentyfive surveyed companies use specialized Business Intelligence software for storing and analysing big data, with locally operated and cloud-based solutions being represented to a similar extent. Thus, although large suppliers of big data technologies, such as Microsoft or Oracle, have focused mainly on cloud platforms in recent years, it is clear that cloud solutions in the domain of big data are not yet definitely preferred in the Czech industrial companies.

Figure 2 demonstrates that the integration between the internal information systems of the responding companies is most often implemented in the form of database interconnection. Traditional solutions consisting in generating and importing files, whether structured (XML, JSON, EDI standards) or in the simple csv format, are also used relatively intensively. On the other hand, more modern integration methods in the form of web services are used for the needs of in-house system integration in far fewer cases - REST-based services were mentioned in only three cases and SOAPbased services are used by none of the respondents.

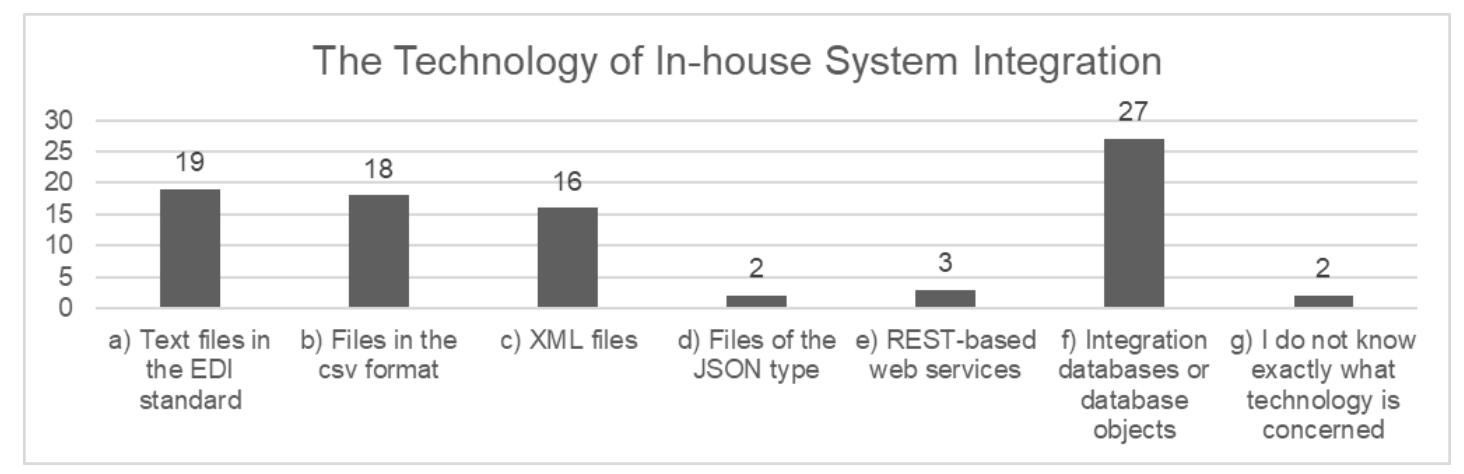

Fig. 2. The frequency of the specific technical solutions within the technology of in-house system integration

If we compare this situation with the technical solutions used for the needs of inter-company integration, the frequency of which is shown in Figure 3, it becomes apparent (of course, taking into account the fact that the overall frequency of inter-company integration solutions is lower, as this technology is significantly less used compared to in-house system integration, as evidenced by the answers to Question 1) that the big difference is mainly in the rate of the use of database integration. It is very frequent in the case of in-house integration, but it is rarely used for interconnection with business partners' systems, despite the fact that it has a number of advantages over other solutions, for example, it can transfer large volumes of data without negative impacts on performance, or the fact that database technologies are standardized to a large extent, which brings significant simplification in the design and implementation of interconnections.

However, text files in the EDI format are also used intensively in inter-company integration, which is probably related to the fact that their use is widespread especially in the automotive sector, which plays a significant role in the manufacturing industry of the Czech Republic. A rather surprising fact is that none of the surveyed companies use web services for the inter-company system integration, which are technically suitable for this purpose and are currently a standard part of many ERP systems as their API layer.

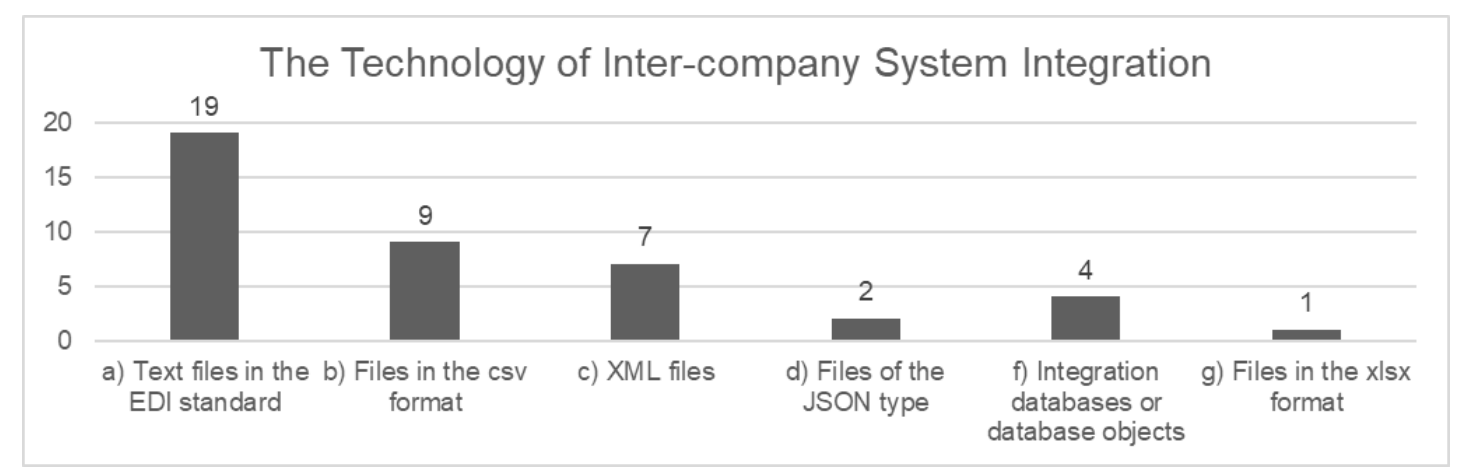

Fig. 3. The frequency of the specific technical solutions within the technology of inter-company system integration 
Figure 4 shows the frequency of technical solutions used by the respondents' companies in the domain of automatic identification and data capture. The most used solution is definitely the identification of objects and activities by barcodes or QR codes. The high rate of use corresponds to a long-term trend in WMS and MES systems, where the manipulation of individual objects or the recording of operations in production through code scanning instead of manual data entry is one of the basic functionalities used because of the higher speed and lower error rate compared to manual data entry.

In contrast, the second most common solution, image recognition for document mining, is significantly newer and its wider use in companies has only been made possible by the increase in computing power of hardware resources in recent years. The fact that even in such a short time this solution has become relatively widely used is evidence of the attractiveness of this technology, which allows significant time savings for office staff. Solutions based on other principles, with the exception of radio-frequency identification, which is used by six of the companies surveyed, occurred only sporadically among the respondents.

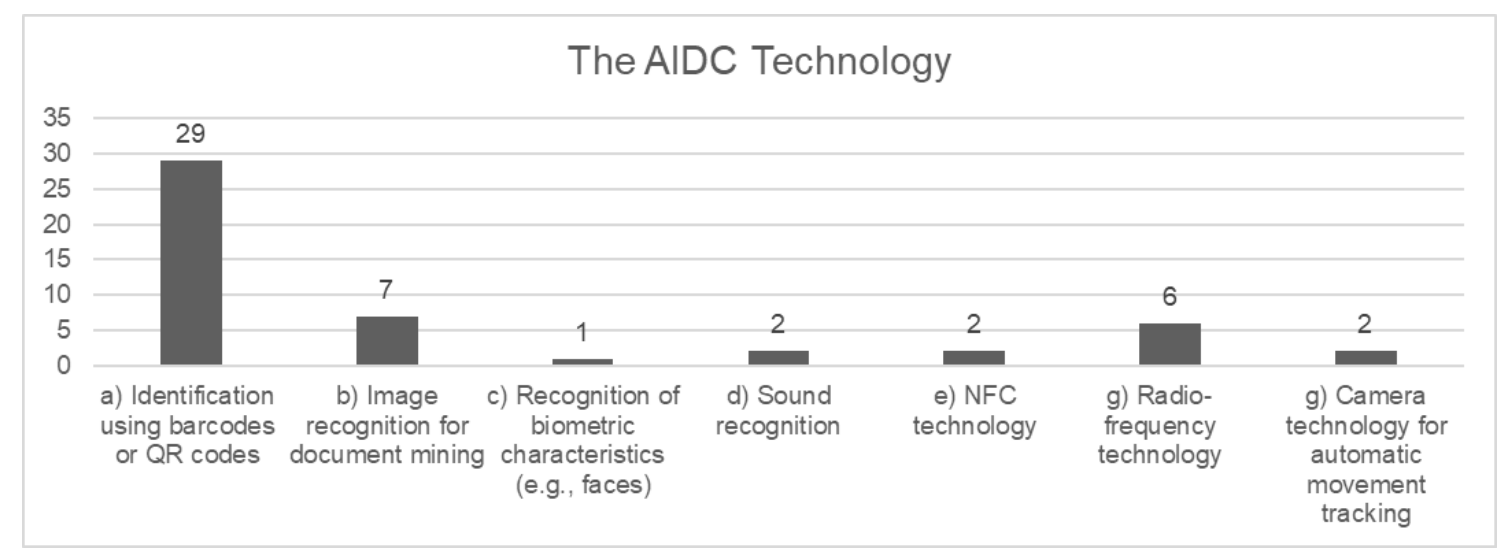

Fig. 4. The frequency of the specific technical solutions within the AIDC technology

\section{Conclusion}

The paper has presented the research aiming to identify Industry 4.0 technologies that are directly related to ERP systems and to determine the current state of the use of these technologies by industrial enterprises in the Czech Republic. Based on the search of available literature and the subsequent analysis, the basic Industry 4.0 technologies were identified at first, and then those related to the management of administrative processes and/or the storage and analysis of centralized data, which are the traditional tasks of ERP systems, were identified. These technologies are big data, system integration, cloud, and automatic identification and data capture. In the more comprehensive questionnaire distributed to mediumsized and large manufacturing enterprises based in the Czech Republic, enterprises were then asked questions mapping both the extent to which these technologies are used by enterprises and the specific technical solutions chosen by them in this area. The results of the questionnaire survey show that the most used technology is clearly the system integration for in-house purposes.

The research presented in this paper focused on determining the current state of the use of the Fourth Industrial Revolution technologies. Analysing the causes of this state in order to obtain answers to the question of why other technologies, besides the in-house system integration, are not used more intensively and how enterprises make decisions in choosing a particular technical solution when deploying a particular technology appears to be a possible direction for further research.

\section{References}

[1] Vacek, J. (2017). On the Road: from Industry 4.0 to Society 4.0, Trendy v Podnikání, Vol. 7, No. 4, pp. 43-50, ISSN 1805-0603.

[2] Fukuda, K. (2020). Science, technology and innovation ecosystem transformation toward society 5.0, International Journal of Production Economics, Vol. 220, ISSN 0925-5273, DOI: 10.1016/j.ijpe.2019.07.033

[3] Takakuwa, S.; Veza, I. \& Celar, S. (2018). Industry 4.0 in Europe and Asia, Proceedings of the 29th International DAAAM Symposium "Intelligent Manufacturing \& Automation", 24-27th October 2018, Zadar, Croatia, ISSN 1726-9679, ISBN 978-3-902734-20-4, Katalinic, B. (Ed.), pp. 61-69, Daam International, Vienna, DOI: 10.2507/29th.daaam.proceedings.009

[4] Sawaragi, T.; Horiguchi, Y. \& Hirose, T. (2020), Design of Productive Socio-Technical Systems by Human-System Co-Creation for Super-Smart Society, IFAC PapersOnLine, Vol. 53, No. 2, pp. 10101-10108, ISSN 2405-8963, DOI: 10.1016/j.ifacol.2020.12.2734

[5] Rojko, A. (2017). Industry 4.0 Concept - Background and Overview, International Journal of Interactive Mobile Technologies, Vol. 11, No. 5, pp. 77-90, ISSN 1865-7923. 
[6] Vaidya, S.; Ambad, P. \& Bhosle, S. (2018). Industry 4.0 - A Glimpse, Procedia Manufacturing, Vol. 20, pp. 233238, ISSN 2351-9789, DOI: 10.1016/j.promfg.2018.02.034

[7] Leyh, Ch.; Schäfer, T.; Bley, K. \& Forstenhäusler, S. (2017). Assessing the IT and Software Landscapes of Industry 4.0-Enterprises: The Maturity Model SIMMI 4.0. In Information technology for management: new ideas and real solutions, E. Ziemba (Ed.), pp. 103-119, Springer, ISBN 978-3-319-53076-5, Cham.

[8] Inkermann, D.; Schneider, D.; Martin, N.L.; Lembeck, H.; Zhang, J. \& Thiede, S. (2019). A framework to classify Industry 4.0 technologies across production and product development, Procedia CIRP, Vol. 84, pp. 973-978, ISSN 2212-8271, DOI: 10.1016/j.procir.2019.04.218

[9] Zhong, R.Y.; Xu, X.; Klotz, E. \& Newman, S.T. (2017). Intelligent Manufacturing in the Context of Industry 4.0: A Review, Engineering, Vol. 3, pp. 616-630, ISSN 2095-8099, DOI: 10.1016/J.ENG.2017.05.015

[10] Bajic, B.; Cosic, I.; Katalinic, B.; Moraca, S., Lazarevic, M. \& Rikalovic, A. (2019). Edge Computing vs Cloud Computing: Challenges and Opportunities in Industry 4.0, Proceedings of the 30th International DAAAM Symposium "Intelligent Manufacturing \& Automation", 23-26th October 2019, Zadar, Croatia, ISSN 1726-9679, ISBN 978-3-902734-22-8, Katalinic, B. (Ed.), pp. 864-871, Daam International, Vienna, DOI: 10.2507/30th.daaam.proceedings. 120 .

[11] Egger, J. \& Masood, T. (2020). Augmented reality in support of intelligent manufacturing - a systematic literature review, Computers \& Industrial Engineering, Vol. 140, pp. 1-22, ISSN 0360-8352, DOI: 10.1016/j.cie.2019.106195

[12] Novák, P.; Vyskočil, J. \& Wally, B. (2020). The Digital Twin as a Core Component for Industry 4.0 Smart Production Planning, IFAC PapersOnLine, Vol. 53, No. 2, pp. 10803-10809, ISSN 2405-8963, DOI: 10.1016/j.ifacol.2020.12.2865

[13] Schmidbauer, Ch.; Komenda, T. \& Schlund, S. (2020). Teaching Cobots in Learning Factories - User and UsabilityDriven Implications, Procedia Manufacturing, Vol. 45, pp. 398-404, ISSN 2351-9789, DOI: 10.1016/j.promfg.2020.04.043

[14] Esmaeilian, B.; Sarkis, J.; Lewis, K. \& Behdad, S. (2020). Blockchain for the future of sustainable supply chain management in Industry 4.0, Resources, Conservation \& Recycling, Vol. 163, pp. 1-15, ISSN 0921-3449, DOI: 10.1016/j.resconrec.2020.105064

[15] Rüssman, M.; Lorenz, M.; Gerbert, P.; Waldner, M.; Engel, P.; Harnisch, M. \& Justus, J. (2015). Industry 4.0: The Future of Productivity and Growth in Manufacturing Industries, Available from: https://www.bcg.com/publications/2015/engineered_products_project_business_industry_4_future_productivity_g rowth_manufacturing_industries Accessed: 2021-09-09

[16] da Silva, E.R.; Shinohara, A.C.; Nielsen, Ch.P.; Pinheiro de Lima, E. \& Angelis, J. (2020). Operating Digital Manufacturing in Industry 4.0: the role of advanced manufacturing technologies, Procedia CIRP, Vol. 93, pp. 174179, ISSN 2212-8271, DOI: 10.1016/j.procir.2020.04.063

[17] Büchi, G.; Cugno, M. \& Castagnoli, R. (2020). Smart factory performance and Industry 4.0, Technological Forecasting \& Social Change, Vol. 150, pp. 1-10, ISSN 0040-1625, DOI: 10.1016/j.techfore.2019.119790

[18] Polívka, M. \& Dvořáková, L. (2019). Využití automatické identifikace a sběru dat prostřednictvím radiofrekvenčních technologií v prostředí průmyslu 4.0, Trendy v podnikání, Vol. 9, No. 2, pp. 53-61, ISSN 18050603.

[19] Masood, T. \& Sonntag, P. (2020). Industry 4.0: Adoption challenges and benefits for SMEs, Computers in Industry, Vol. 121, pp. 1-12, ISSN 0166-3615, DOI: 10.1016/j.compind.2020.103261

[20] Alcácer, V. \& Cruz-Machado, V. (2019). Scanning the Industry 4.0: A Literature Review on Technologies for Manufacturing Systems, Engineering Science and Technology, an International Journal, Vol. 22, pp. 899-919, ISSN 2215-0986, DOI: 10.1016/j.jestch.2019.01.006 